Documenta \& Instrumenta

ISSN-e: 1697-3798

http://dx.doi.org/10.5209/docu.75470

\title{
La visita del arzobispo Pedro de Castro al Tribunal Eclesiástico de Granada en $1590^{1}$
}

\author{
María Luisa García Valverde ${ }^{2}$
}

Recibido: 14 de octubre de 2020 / Aceptado: 12 de abril de 2021

Resumen. La llegada del arzobispo Pedro de Castro Vaca y Quiñones a Granada a finales de 1589 marca el inicio de un gran programa reformador del arzobispado en el que no pueden faltar las instituciones que gestionan el gobierno de la diócesis. Para llevarla a cabo necesita conocer la situación en que se encuentra el arzobispado y sus organismos a través de la realización de una serie de visitas pastorales entre las que destacan las realizadas a la Contaduría y al personal de la Audiencia: provisores, visitadores, fiscales, notarios, alguaciles y ministros del anterior arzobispo Juan Méndez Salvatierra y de su sede vacante. Es cierto que la finalidad de la visita es conocer la actuación de los notarios en el desempeño de sus oficios e indicar si lo han desempeñado con corrección o no tras el pontificado del anterior arzobispo y de su sede vacante. Pero también es cierto que en una diócesis como Granada ésta era la forma más rápida de sacar a la luz las desviaciones cometidas en las formas de actuar del Tribunal y un medio para proyectar la reforma de las instituciones. Reforma que quedó sin realizar y cuyas consecuencias aún se vislumbran a finales del siglo XVIII.

Palabras clave. Notarios eclesiásticos; visita tribunal eclesiástico; juicio de residencia; Iglesia; Granada.

\section{[en] The archbishop Pedro de Castro's visit to the Ecclesiastical Court of Granada in 1590}

\begin{abstract}
Archbishop Pedro de Castro Vaca y Quiñones' arrival in Granada in 1589 marks the beginning of a large reformer program of the archbishopric. To carry it out, he needs to know the situation in which the diocese and its organisms are found, through the realization of several pastoral visits, among which are those made to the Accounting and the staff of the Audiencia: provisors, visitors, prosecutors, notaries, bailiffs and ministers of the former Archbishop Juan Méndez Salvatierra and his vacant seat. It's true that the purpose of this visit was to know the actions of notaries in the performance of their jobs and to indicate whether or not have performed it correctly. But it's also true that in a diocese like Granada this was the fastest way to see the mistakes made in the court's action and thus carry out the reform of the Institutions. This reform was not carried out and its consequences are still looming at the end of the eighteenth century.
\end{abstract}

Keywords. Ecclesiastical notaries; visit ecclesiastical court; residence trials; Church; Granada.

1 El presente trabajo ha sido realizado en el marco del Proyecto Iglesia y Escritura en el Occidente Peninsular (Castilla y Portugal). Siglos XII-XVII (HAR2017-85025-P), financiado por el ministerio de Economía y Competitividad.

2 Universidad de Granada (España)

E-mail: marisagv@ugr.es 
Sumario. 1. Introducción. 2. Los notarios del tribunal eclesiástico. 3. Procedimiento para llevar a cabo la visita. 4. Convocatoria, nombramiento de juez y notario de visita. 5. Visita al oficio. 6. La visita secreta. 7. Las probanzas. 8. Los testigos. 9. Relación de cargos. 10. El período de prueba. 11. Sentencia. 12. Visita al resto de notarios. 13. Consecuencias de la visita. 14. Bibliografía.

Cómo citar. M. L. García Valverde, "La visita del arzobispo Pedro de Castro al Tribunal Eclesiástico de Granada en 1590”, Documenta \& Instrumenta, 19 (2021), pp. 109-130. 


\section{Introducción}

La llegada, a finales de 1589, del arzobispo Pedro de Castro Vaca y Quiñones ${ }^{3}$ a la diócesis de Granada significó la puesta en funcionamiento de los preceptos establecidos en el Concilio de Trento. Hombre inteligente, de un gran pragmatismo y una profunda formación jurídica su pontificado se caracteriza por una primera etapa, reformista de todas las instituciones eclesiásticas y una segunda, a partir de 1595, dominada por los descubrimientos del monte Valparaíso, los conocidos libros plúmbeos, que acabarán focalizando la vida y las actuaciones del arzobispo y que, a la larga, provocarán su traslado a la sede hispalense $e^{4}$.

Dentro de su primera etapa reformadora se ocupó de las instituciones que gestionan el gobierno de la diócesis; de los libros de la administración dándoles una nueva redacción, creando otros nuevos como el tercer libro becerro de memorias perpetuas en el que incluyó un total de cincuenta patronatos que no estaban recogidos en ningún lugar y de los que se había perdido toda referencia e intentó adaptar los notarios apostólicos a la forma de actuar de los escribanos públicos. Para poner en funcionamiento este amplio programa necesita conocer de primera mano el funcionamiento de la diócesis motivo por el cual proyectó y realizó cuatro visitas generales al arzobispado, una visita general a la Contaduría ${ }^{5}$ y otra al personal de la Audiencia del anterior arzobispo Juan Méndez Salvatierra y de su sede vacante ${ }^{6}$.

\section{Los notarios del tribunal eclesiástico}

Durante el siglo XVI el Tribunal Eclesiástico está constituido por tres salas atendidas por un personal estable entre los que se encuentran tres notarios propietarios; dos de ellos prestan sus servicios en las salas de lo civil y de lo criminal y el tercero dedicado, exclusivamente, a los asuntos civiles y criminales del personal eclesiástico de la diócesis. Dependiendo de los dos notarios propietarios encargados de los asuntos civiles y criminales habrá dos oficiales o "notarios de cajón" para el registro de los autos y escrituras que ingresan en los respectivos Oficios, varios notarios receptores para la realización de las probanzas y un repartidor que tiene como misión la distribución de los negocios que ingresan en el Tribunal siguiendo un orden

3 M. A. LÓPEZ RODRÍGUEZ, Los arzobispos de Granada: Retratos y Semblanzas, Granada, 1993, p. 103.

4 Para ampliar este tema véase J. ANTOLINEZ, Historia eclesiástica de Granada [1611]. Estudio y edición de Manuel Sotomayor, Granada, Universidad, 1996; M. BARRIOS AGUILERA, La invención de los libros plúmbeos. Fraude, historia y mito, Granada, Universidad, 2011; M. BARRIOS AGUILERA, "Pedro de Castro y los plomos del Sacro Monte: invención y paradoja. Una aproximación crítica", Los plomos del Sacro Monte. Invención y tesoro. Edición de Manuel Barrios Aguilera y Mercedes García-Arenal, Biblioteca de estudios moriscos, 17-50, Valencia, Universidad de Valencia, 2006; D. CABANELAS RODRÍGUEZ "Intento de supervivencia en el ocaso de una cultura: los libros plúmbeos de Granada, Nueva revista de Filología Hispánica, 30.2(1981), pp. 334 - 358; D. N. HEREDIA BARNUEVO, Místico ramillete. Vida de don Pedro de Castro, fundador del Sacro Monte [1791]. Estudio preliminar y álbum iconográfico de Manuel Barrios Aguilera, Colección Archivo, Granada, Universidad, 1998.

5 Archivo Histórico Diocesano de Granada (AHDG). Leg. 89-R-4. Relaçión del estado y gouierno de la Yglesia Metropolitana del arçobispado de Granada. fol $24 \mathrm{r}$.

6 AHDG. Leg. 230-F. Rollo de los autos de la bisita hecha por el liçenciado Antolínez, bisitador del arçobispado de Granada contra los probisores, bisitadores, fiscales, notarios y alguaciles y los maestros offiçiales del arçobispado de Granada. 1590. 
territorial y no cronológico como, tradicionalmente, reclaman los notarios. Por último, y con carácter itinerante, encontramos dos nuncios o cursores que sirven los diferentes Oficios del Tribunal y tienen como misión realizar las citaciones.

Así podemos establecer un cuadro marco del Tribunal en cuanto a notarios se refiere que en el momento de la visita de 1590 estaba formado por:

\begin{tabular}{|c|c|c|c|c|c|}
\hline $\begin{array}{c}\text { Notarios } \\
\text { propietarios }\end{array}$ & $\begin{array}{l}\text { Oficiales } \\
\text { de cajón }\end{array}$ & $\begin{array}{l}\text { Notarios } \\
\text { receptores }\end{array}$ & $\begin{array}{c}\text { Notarios } \\
\text { repartidores }\end{array}$ & $\begin{array}{l}\text { Notarios sin } \\
\text { adscripción } \\
\text { conocida }\end{array}$ & Nuncios \\
\hline $\begin{array}{c}\text { - Lorenzo } \\
\text { Adriano. } \\
\text { - Urbán } \\
\text { Pérez. } \\
\text { - Fernando } \\
\text { Pérez } \\
\text { Magaña. }\end{array}$ & $\begin{array}{c}\text { - Pedro } \\
\text { Herriega } \\
\text { Valdés. } \\
\text { - Cristóbal } \\
\text { de Castilla. }\end{array}$ & $\begin{array}{c}\text { - Jerónimo } \\
\text { Serrano de } \\
\text { Vargas. }\end{array}$ & $\begin{array}{l}\text { - Luis de } \\
\text { Prado. }\end{array}$ & $\begin{array}{c}\text { - Nicolás } \\
\text { Valdés }{ }^{7} . \\
\text { - Juan de } \\
\text { Montiel. } \\
\text { - Pedro Ca- } \\
\text { rrillo. } \\
\text { - Antonio } \\
\text { Gudiel. }\end{array}$ & $\begin{array}{c}\text { - Fabián } \\
\text { de } \\
\text { Baños. } \\
\text { - Juan } \\
\text { Villar } \\
\text { Godoy. }\end{array}$ \\
\hline
\end{tabular}

Cuadro ${ }^{0} 1$.

Será durante el siglo XVII cuando se produzca la primera reforma del Tribunal. Así durante el pontificado de Martín de Ascargorta (1693-1719) se incrementó el número de notarios pasando de tres a cuatro notarios mayores asistidos cada uno de ellos por un oficial y seis receptores para la redacción de las confesiones y declaraciones judiciales y otros seis notarios, sin adscripción concreta para asistir a los abogados y procuradores ${ }^{8}$. Sin embargo, tendremos que esperar a 1762 durante el pontificado de Pedro Antonio Barroeta y Ángel para encontrar la gran reforma del Tribunal.

\section{Procedimiento para llevar a cabo la visita}

La Sesión XXIV, cap. XVI del Concilio de Trento legisla sobre la obligación de los obispos a realizar visitas a sus diócesis por si o por medio de sus vicarios o visitadores con el objetivo de introducir la doctrina sana y católica, expeler las herejías y promover las buenas costumbres. Igualmente, en la sesión XXII, cap. X del mismo Concilio se legisla sobre la obligación, por parte de los ordinarios, de realizar exámenes para determinar la destreza de los notarios eclesiásticos aunque ya hubiesen sido nombrados por la autoridad apostólica, imperial o real ${ }^{9}$. Medidas que se justi-

En este momento existen dos notarios que comparten el mismo nombre. El primero fue notario propietario y éste sin adscripción conocida.

8 Archivo Apostólico Vaticano (AAV). Sacra Congr. Concilii Relationes, Leg. 370 A. Visita ad limina de Martín de Ascargorta de 1699, fols. 193-202.

9 EL SACROSANTO Y ECUMÉNICO CONCILIO DE TRENTO. Traducido por Ignacio López de Ayala. $3^{\mathrm{a}}$ ed. Barcelona, imprenta de Sierra y Martí, 1828, p. 257. 
fican por parte de los padres conciliares por la necesidad de terminar con los daños ocasionados por la impericia de los notarios ${ }^{10}$.

En esta misma línea de control y examen a los notarios se sitúan las Constituciones surgidas en los Sínodos y Concilios Provinciales celebrados tras la conclusión del tridentino que se conforman como un complejo sistema jurídico ordenado al gobierno y a la reforma de la diócesis ${ }^{11}$. Normativa que va a desencadenar una serie de actuaciones para poner fin a la falta de especialización de los notarios eclesiásticos y llevar el control de sus actuaciones.

Así, y para el caso de Granada, serán el Concilio Provincial de 1565 y el Sínodo de 1582 quienes vean la necesidad de reorganizar la diócesis y en concreto los notarios eclesiásticos. Los padres sinodales se quejan de su excesivo número y de los desórdenes que provocan y por ello plantean la necesidad de incluir en las nuevas Constituciones un capítulo sobre la organización de los notarios y otro sobre la reorganización del Tribunal Eclesiástico a la vez que establecen el control de estos oficiales a través de la obligación de realizar visitas periódicas para proceder al examen de sus actuaciones ${ }^{12}$.

El rollo de los autos de la bisita hecha por el liçenciado Antolínez, bisitador del arçobispado de Granada contra los probisores, bisitadores, fiscales, notarios y alguaçiles y los más offiçiales del dicho arçobispado ${ }^{13}$ es un grueso volumen de seiscientos noventa y seis folios que se conserva en el Archivo Histórico Diocesano de Granada en el que se recoge todas las actuaciones de la visita decretada por Pedro de Castro a la Audiencia arzobispal en 1590. Constituye la tercera de las realizadas tras la aprobación del Concilio de Trento. Las dos anteriores se desarrollaron durante el pontificado de Juan Méndez Salvatierra (1577-1588), la primera siendo chantre Alonso de Vílchez Pacheco, en torno a 1581, y la segunda siendo provisor Antonio de Barba ya en 1586 de las que hasta el momento no se ha localizado ningún tipo de documentación; la tercera, ésta que estamos estudiando, se produjo recién llegado el siguiente arzobispo a Granada, Pedro de Castro, y supuso su primer contacto con las instituciones que gobiernan la diócesis en estos momentos.

La visita de 1590 supone, como cualquier otra visita o residencia, un instrumento de control para los oficiales y jueces una vez concluido su periodo de actividad en el que se van a poner de manifiesto las posibles quejas y reclamaciones derivadas de su gestión en el Tribunal Eclesiástico ${ }^{14}$. De su resultado dependerá la permanencia en su oficio y el recibimiento de mercedes y cargos superiores, o que quede imposibilitado para ejercer otras funciones ${ }^{15}$.

10 F. L. FERRARIS, Bibliotheca canonica, juridica, moralis, theologica, necnon ascetica, polemica rubricistica, historica..., vol. V, Roma, 1760, p. 226 y M. L. GARCÍA VALVERDE, "Los notarios apostólicos de Granada a través de las legislaciones civil y eclesiástica", Historia, Instituciones, Documentos, no 37 (2010), pp. 87108. DOI: http://dx.doi.org/10.12795/HID.

11 R. M. PÉREZ GARCÍA, "Visita pastoral y contrarreforma en la archidiócesis de Sevilla, 1600-1650", Historia, Instituciones, Documentos, no 27(2000), pp. 205-234. DOI: http://dx.doi.org/10.12795/HID.

12 M. L. GARCÍA VALVERDE, "Los notarios apostólicos de Granada a través de las legislaciones civil y eclesiástica", Historia, Instituciones, Documentos, no 37 (2010), pp. 87-108. DOI: http://dx.doi.org/10.12795/ HID.

13 AHDG. Leg. 230-F.

14 G. de MONTERROSO Y ALVARADO,Pratica ciuil y criminal e instructión de escriuanos: diuidida en nueue tractados. Valladolid, por Francisco Fernández de Cordoba, 1563, fol. 242r.

15 M. J. COLLANTES DE TERÁN DE LA HERA, "El juicio de residencia en Castilla a través de la doctrina jurídica de la Edad Moderna", Historia, Instituciones, Documentos n 25 (1998) pp. 151-184. https:// dialnet.unirioja.es/servlet/articulo? codigo $=634119$ (consultado abril de 2020). 
La visita, al igual que ocurre en la residencia para los oficiales públicos, debe realizarse en un plazo prefijado con anterioridad, unos treinta días como máximo ${ }^{16}$, pero la complejidad de la misma y la cantidad de recursos contra las sentencias pronunciadas por el juez motivaron su retraso hasta comienzos de 1592.Está estructurada en una serie de etapas que se van sucediendo de forma simultánea y que podemos clasificar en: decreto ordenando el inicio de la visita, nombramiento de juez y notario de visita, visita al oficio, visita secreta, relación de cargos, alegaciones contra los delitos y sentencia.

\section{Convocatoria, nombramiento de juez y notario de visita}

A pesar de que la estructura general de la visita guarda muchas semejanzas con las realizadas a los oficiales de la corona la tramitación es bastante más simplificada. Así la designación de juez se ve reducida a la entrega de la comisión de su nombramiento y al acatamiento del mismo por parte del designado. Desaparece, por tanto, el depósito de la fianza obligatoria en otras residencias y el desplazamiento del juez en persona a otros lugares de la jurisdicción de la diócesis, acto en el que será sustituido por los vicarios territoriales del arzobispado ${ }^{17}$.

Siguiendo el esquema anteriormente expuesto, la primera medida que toma Pedro de Castro a los pocos días de su llegada a la ciudad de Granada es ordenar una visita a todo el personal del Tribunal Eclesiástico designando al licenciado Justino Antolinez como juez visitador de la misma.

Antolínez es sin duda la persona que mejor encarna las características morales, estamentales y técnicas ${ }^{18}$ que todo juez debe cumplir y que vienen enumeradas en la teoría jurídica. Así para Castillo de Bobadilla éstos deben ser varones temerosos de Dios, amadores de la verdad, enemigos de la avaricia, sabios, de buen linaje y letrados ${ }^{19}$. En esta misma línea se sitúa Solórzano y Pereyra que establece que deben ser hombres de gran puesto y autoridad y expertos en materia de tribunales $y$ de entera satisfacción en vida y costumbres ${ }^{20}$. En este sentido Antolínez es el hombre de confianza del arzobispo, además posee los conocimientos técnicos suficientes para desempeñar este cargo pues no podemos olvidar que es letrado de Cámara del arzobispo, jurisconsulto de Cámara en las Chancillerías de Valladolid y en la de Granada y profesor de Derecho Canónico en la Universidad; por tanto concentra en su persona todas las cualidades necesarias para ser designado juez y, por tanto, se configura como la persona más adecuada, tal vez la única, que puede realizar esta visita.

Al igual que sucede en las demás visitas o residencias el visitador debe ir acompañado por uno o dos notarios hábiles y suficientes que actúan en todo el procedimiento. En ésta encontramos a dos notarios: Jerónimo de Herrera, secretario del propio arzobispo, que actúa en la visita al oficio y Antonio Díaz Campomanes, escribano del rey, que lo hace en la visita secreta.

\footnotetext{
16 El plazo normal para la residencia era de 30 días pero en esta se incrementó hasta los 40 .

17 G. de MONTERROSO Y ALVARADO, Pratica ciuil y criminal..., fol. 242r.

18 M. J. COLLANTES DE TERÁN DE LA HERA, "El juicio de residencia...", p. 157.

19 M. J. COLLANTES DE TERÁN DE LA HERA, "El juicio de residencia...,", p. 157.

20 M. J. COLLANTES DE TERÁN DE LA HERA, “El juicio de residencia...”, p. 157.
} 
En la provisión de nombramiento también se establece el tiempo para la realización de la residencia. En un primer momento se concedió un plazo de cuarenta días para llevarla a cabo. Plazo insuficiente que debió ser prorrogado en numerosas ocasiones hasta septiembre de 1591.

Una vez nombrado el juez, los notarios y establecidos los plazos para su realización, se procede a la publicación de la residencia. Acto que se desarrolla en dos fases consecutivas. La primera tiene lugar en el momento de la lectura solemne del decreto de la convocatoria de la visita durante la misa mayor que se celebre en el Sagrario el primer día de fiesta tras la convocatoria en alta boz para que todos lo oyesen, para que biniese a notiçia de todos ${ }^{21} \mathrm{y}$, la segunda, su publicación con la colocación de la copia del mismo en la puerta del templo.

En un primer momento la visita va a estar dirigida a los notarios propietarios: Lorenzo Adriano, Urbán Pérez y Fernando Pérez Magaña aunque posteriormente se extendió al resto de notarios: los "notarios del cajón" que ejercen el cargo de oficiales, los nuncios y al resto de los notarios ${ }^{22}$.

\section{Visita al oficio}

La visita al oficio comienza con la clausura de las dependencias de la Audiencia. El juez, acompañado por dos testigos también notarios del propio Tribunal, recoge las llaves de los armarios y algunos papeles de interés que están en las oficinas con la intención de no permitir extracciones ni reintegros en las actuaciones, ni manipulación de las mismas, y así evitar posibles correcciones y encubrimientos producidos por una mala praxis notarial.

Como es de suponer, el Tribunal no puede paralizarse por la visita a sus oficiales por eso es normal encontrar peticiones de los notarios al juez para que abra la Audiencia y así recoger algunos expedientes que se están tramitando. Extracción de documentación que se realiza diariamente de aquellas causas que ya han sido visitadas y siempre bajo la supervisión directa de Antolínez. La visita a los oficios comenzó el 7 de diciembre de 1590 y se prolongó hasta el 11 de enero del año siguiente con varias prórrogas solicitadas al visitador dada la gran cantidad de documentación que debía ser inspeccionada.

Los expedientes y causas son examinados siguiendo un riguroso orden establecido de antemano. En primer lugar se procede a la revisión de los tramitados o en trámite que están en poder de un notario distinto al que le habían sido repartidos. Así por ejemplo, en la visita a Lorenzo Adriano lo primero que se inspecciona es la documentación que está en el oficio de Urbán Pérez. A su vez, la visita a este conjunto sigue un orden preestablecido. Así en primer lugar se examinan las causas incoadas entre eclesiásticos y seglares; luego las producidas por disputas entre seglares, fundamentalmente, causas matrimoniales $\mathrm{y}$, por último, los pleitos de carácter ejecutivo.

Tras el examen de este bloque se pasa a inspeccionar los expedientes que están en poder del propio notario sobretodo los que hacen referencia a causas de tipo matrimonial. A continuación, las causas que están en la Audiencia: amancebamien-

21 AHDG. Leg. 230-F. Decreto de 7 de Diciembre de 1590.

$22 \quad$ Véase cuadro $n^{\circ} 1$. 
tos, sacrilegios, restituciones de iglesias, encubridores, alcahüetas, cumplimiento de testamentos y ejecuciones. La inspección de los expedientes matrimoniales ocupa un lugar destacado. En ellos se comprueba si están todos repartidos; si las peticiones, dichos de los testigos y confesiones de los contrayentes están firmadas y rubricadas por el notario y si los autos han sido proveídos por el provisor. Por último, se visitan los papeles y pleitos que acaban de ingresar en el Tribunal y las denuncias indicando las faltas y errores en su expedición.

Una vez visitados todos los expedientes y causas y con el fin de tener identificados fácilmente los errores cometidos se acostumbra a anotar en la cabeza del proceso las faltas observadas en su tramitación: está por repartir, sin comissión; anotaciones que serán rubricadas por el juez o por el notario de la visita y que servirán para realizar la relación de cargos ${ }^{23}$.

Una vez concluida la visita a los expedientes y papeles del oficio el juez hace una primera relación de cargos que se entrega a cada notario. En ella se hace la enumeración exhaustiva de las faltas cometidas en la tramitación de cada expediente. Esta primera relación de cargos también sirve para ordenar la entrega, en un plazo perentorio de tres días, de los protocolos e inventarios de las escrituras.

Tras esto, el notario visitado hace la relación de descargos y presenta las preguntas por las que deben ser examinados los testigos por él seleccionados. Éstas van dirigidas a demostrar la calidad de su persona, a defender el desempeño de su oficio y a demostrar que siempre ha actuado de acuerdo a la costumbre del Tribunal sin contravenir las Constituciones Sinodales del Arzobispado.

Para que los notarios puedan cumplir lo establecido en esta primera relación de cargos, el juez concede un plazo de tres días para que presenten sus protocolos e inventarios, plazo que resultó ser insuficiente por lo que debió ser ampliado en varias ocasiones. A mediados de febrero aún no se habían entregados a Antolínez los protocolos por lo que les volvió a conceder un nuevo plazo, esta vez de treinta días, solicitando de nuevo su entrega. Decreto que, al igual que los anteriores, no fue obedecido por lo que el juez volvió a concederles un último plazo para su depósito en el Tribunal bajo pena, esta vez, de dos mil maravedíes para aquellos que no cumplieran lo mandado ${ }^{24}$.

\section{La visita secreta}

Tras esta primera fase de inspección de la documentación se pasa a la visita secreta que constituye el núcleo fundamental de la residencia. Se inicia en un plazo no superior a quince días desde la publicación de la visita y no debe de durar más de treinta desde su comienzo; consiste en la investigación sobre el cumplimiento de las obligaciones profesionales a través de las probanzas de los testigos ${ }^{25}$.

\footnotetext{
AHDG. Leg. 230-F. Auto de 11 de Diciembre de 1590.

AHDG. Leg. 230-F. Auto de 21 de Enero de 1591.

M. J. COLLANTES DE TERÁN DE LA HERA, “El juicio de residencia...”, pp. 151-184.
} 


\section{Las probanzas}

A lo largo de la visita encontramos dos clases de probanzas que dependen del momento en que se realicen y del grado de relación que los testigos tengan con los notarios. La primera, tiene lugar tras la visita al oficio y durante el periodo de alegaciones una vez concluida la visita secreta. En ella será el propio notario el que presente a los testigos y tiene como misión defender su idoneidad para el desempeño del oficio. La segunda se produce en la visita secreta momento en que cualquier persona que se sienta perjudicada o conozca los hechos investigados tiene la obligación de acudir ante la Audiencia a declarar todo lo que sabe. El procedimiento en ambos casos es muy semejante, la gran diferencia se produce en cuanto a la redacción de las preguntas.

En el primer caso en que los testigos son afines al notario, las probanzas comienzan con la presentación por parte de los residenciados de las preguntas por las que deben ser examinados los testigos. Como es de suponer en ellas se insiste en la calidad de la persona, su buena gestión en el desempeño del oficio encomendado y en la ausencia de delitos y coacciones que vayan en contra de la legislación aprobada.

En el segundo caso, el interrogatorio de la visita secreta sigue los modelos establecidos en los manuales de práctica forense o los utilizados en las visitas anterio$\mathrm{res}^{26}$. Las preguntas son elaboradas por el juez siendo unas de carácter general en las que se interroga sobre si conocen personalmente a los oficiales o si tienen contra ellos animadversión o amistad manifiesta y otras de carácter particular sobre cada uno en concreto. Así, en ésta de 1590, se va a continuar con la forma establecida en anteriores visitas presentando dos tipos de preguntas que van a depender de si los testigos son notarios o no.

A los notarios se les va a interrogar por el tiempo que han usado el oficio y si los papeles y procesos que han pasado ante ellos los tienen inventariados y en orden. De igual forma se le va a preguntar sobre el cumplimiento de las Constituciones Sinodales en concreto las relativas a la prohibición de tomar en minuta los poderes y declaraciones de los testigos, el repartimiento de los pleitos, tener los pleitos bien ordenados, juntos y cosidos y tener bien custodiados los protocolos, las bulas, poderes, sentencias y cualquier escritura original que presenten las partes.

En este sentido Lorenzo Adriano declara que los anteriores propietarios del oficio Diego Cortés ${ }^{27}$ y Nicolás de Valdés, no le habían entregado ni el inventario ni protocolo alguno al igual que él mismo no lo había hecho con su sustituto Urbán Pérez $^{28}$. Éste, en clara contradicción con el anterior, declara que ha recibido una gran cantidad de documentación de su antecesor y que al estar toda desorganizada ha dedicado mucho tiempo en ponerla en orden, inventariarla y ordenarla. Por último, Fernando Pérez Magaña declara que no tiene memorial de los pleitos que ante él han pasado y que sus antecesores no le han entregado ni memoriales ni pro-

26 G. de MONTERROSO Y ALVARADO, Pratica ciuil y criminal... fol. 246r, P. MELGAREJO MANRIQUE DE LARA, Compendio de contratos públicos, autos de participaciones, ejecutivos y de residencias, con el género del papel sellado que a cada despacho toca, $15^{\mathrm{a}}$ impresión. Madrid, Pedro José Alonso y Padilla, librero, 1748. Libro IV, pp. 357-360.

27 Fue notario apostólico hasta el momento de su fallecimiento en 1585.

28 AHDG. Leg. 230-F. Información de la visita secreta de Lorenzo Adriano (14 de Diciembre de 1590). 
cesos. Por lo demás todos coinciden en que han ejercido bien sus oficios respetando las normas establecidas en las Constituciones y en el arancel del Arzobispado.

Tras el interrogatorio a los notarios propietarios se procede a preguntar al resto de los notarios del Tribunal que declaran que es frecuente tomar en minuta la declaración de testigos, que los notarios de cajón actúan sin comisión, que se cobran derechos en demasía y que los notarios repartidores cometen fraude al no asentar los procesos en los libros registro.

Para el resto de los testigos el interrogatorio va a girar en torno a las infracciones cometidas contra las Constituciones Sinodales. Así a la primera pregunta los testigos deben contestar si los notarios han usado bien sus oficios, y si han continuado sus audiencias. La segunda versa sobre los derechos percibidos en sus actuaciones si han cobrado excesivos derechos o si han cometido falsedad para perjudicar a las partes y la tercera trata sobre los cohechos y si han ocasionado daño o beneficiado a las partes por amistad o enemistad reteniendo los pleitos y escrituras ocasionando con ello daño a las partes.

Tras el interrogatorio a notarios y testigos residentes en Granada se produce la de los más alejados de la misma pero siempre dentro de los límites jurisdiccionales del arzobispado, las tahás de la Alpujarras, Marchena y Alboloduy y las vicarías de Íllora y Alhama. Serán los vicarios pedáneos con competencias para la paz y la justicia, con medios suficientes para su desarrollo y con residencia en las diferentes circunscripciones territoriales de la diócesis quienes realicen las probanzas en los territorios adscritos a su demarcación ${ }^{29}$.En estos casos el interrogatorio comienza con la lectura de la comisión en la que consta la designación del juez de visita y las preguntas por las que van a ser examinados los testigos. Las probanzas siguen un orden preestablecido; comienzan con el examen de los beneficiados de cada lugar y se continúa con los alcaldes y el resto de los vecinos a los que se les interroga si los notarios han desempeñado bien sus oficios, si han inducido a los testigos a jurar en falso o si los derechos cobrados por sus actuaciones se atienen a lo establecido en el arancel de la diócesis. Una vez terminadas las probanzas cerradas y selladas deben ser remitidas al juez para ser incorporadas al proceso.

En cualquier caso el interrogatorio se realiza a puerta cerrada con la única presencia del juez, el notario y de la persona que presta su testimonio y, esporádicamente para los casos de conciencia, con la sola presencia del juez y del interrogado. Éste, al final de su declaración, debe prestar juramento de que mantendrá el secreto sobre lo que le ha sido preguntado para evitar así posibles diligencias o negociaciones con el visitado.

\section{Los testigos}

Los testigos llamados para declarar en este proceso deben ser personas de diferentes estratos sociales que no tengan ni enemistad manifiesta ni sean amigos capitales

29 AAV, Sacra Congr. Concilii Relationes, Leg. 370 A, fols. 193-202. En la visita ad limina de Martín de Ascargorta de 1699 se registra la presencia de veinte vicarías pedáneas con notarios y algunos distribuidos en los lugares distantes de la capital con competencias. 
de los residenciados pero todos deben conocerlos de bista y trato y comunicación ${ }^{30}$. Pedro Melgarejo en su Compendio de contratos públicos fija entre veinticuatro y treinta el número de los testigos que deben ser examinados en la residencia de los corregidores según sean de ciudades pequeñas o populosas, número sensiblemente inferior al que aparece en la visita al Tribunal Eclesiástico ${ }^{31}$.

Para esta visita y sin contar las segundas comparecencias a declarar por llamamiento del juez se presentaron cuarenta y cuatro testigos, número sensiblemente superior a lo que establece la normativa sobre práctica forense ${ }^{32}$. De igual forma se recomienda que una parte de los testigos sean caballeros, otra eclesiásticos, parte abogados y parte vecinos comunes. Por tanto, sociologicamente, podemos decir que son hombres, seglares, normalmente, personal al servicio del Tribunal aunque no faltan eclesiásticos que conocen o han oído hablar de los hechos investigados. Más esporádico resulta el caso de testigos mujeres en los que sólo hemos localizado a tres de entre todos los presentados lo que indica un escaso siete por ciento del total de los interrogados y tan sólo un caso de ese total es el marido el que denuncia en nombre de la mujer. En cuanto a los oficios más representados en la visita encontramos herreros, tenderos, sastres, alcaldes, eclesiásticos y escribanos del rey ${ }^{33}$.

El juez de visita es quien examina personalmente a los testigos debiendo admitir todo lo que dicen tanto a favor como lo que dicen en contra de los examinados, dejando que se expresen con total libertad en todo lo que conocen de primera mano o por oídas. En su declaración los testigos pueden hacerse eco de los rumores que circulan por la Audiencia pero en este caso deben ser ratificados por entre uno o tres testigos que hayan presenciado los acontecimientos denunciados. Así, por ejemplo, en la declaración de Fernando Pérez Magaña, se dice, refiriéndose a uno de los notarios extravagantes, Juan Villar de Godoy, que trabaja en la Audiencia Arzobispal:

Y asimismo éste que declara sabe que a auido en esta Audiencia vn notario extrauagante que se dize Juan Villar de Godoy y se a dicho y murmurado que auía hecho mal su officio. No sabe en que negocios, más que en la Audiencia siempre se a murmurado del y éste que declara nunca a tenido crédito del ni a querido saber de sus negocios por ser tal como tiene referido y muy inquieto ${ }^{34}$.

Pueden, de igual modo, declarar de oídas, transmitiendo lo que otras personas les han comentado sin haber contrastado su veracidad:

a oydo deçir y es pública boz y fama....y que por ser lo que dicho tiene tan público y notorio y auer dello pública voz y fama este testigo no a tenido quenta a las

\footnotetext{
30 AHDG. Leg. 230-F. Preguntas del interrogatorio a la visita secreta y M. S. MARTÍNEZ, Librería de jueces utilísima y universal...Tomo I. Madrid, imprenta de Blas Román, 1774, p. 410 y ss.

31 P. MELGAREJO, Compendio de contratos..., p. 330.

32 M. J. COLLANTES DE TERÁN DE LA HERA, "El juicio de residencia...”, p. 169.

33 Los testigos debían declarar siguiendo un orden establecido: provisores, visitadores, fiscales y notarios.

34 AHDG. Leg. 230-F. Interrogatorio de Fernando Pérez Magaña (21 de Diciembre de 1590).
} 
personas que ansi se quejan en les saber sus nombres más de lo auer oydo decir ansí $^{35}$.

O lo que ellos mismos conocen de primera mano lo qual a bisto más de diez vezes.

... y ansi mismo a bisto a Luis de Prado, notario, que siendo repartidor de la dicha Avdiençia y notario della que no guardaba la fidelidad en el libro que hera obligado porque lo bio que tenía asentados repartimientos en munchos negocios y que no los cargaba en el libro el qual repartidor está obligado.... ${ }^{36}$.

Es frecuente que los testigos no acudan por propia voluntad a prestar declaración ante el juez de la visita bien por miedo a represalias del personal de la Audiencia, bien por no querer ganarse nuevas enemistades por si en un futuro necesitan recurrir a los servicios de estos oficiales o bien por desidia. En estos casos se les declara en rebeldía y se les imponen graves sanciones espirituales y materiales. La más frecuente es la pena de excomunión late sententia contra aquellos que se niegan a comparecer. Es este temor el que posibilita la participación en el proceso de un numeroso grupo de testigos que de otra manera no hubieran participado. En este caso es normal que las declaraciones sean un tanto erráticas. Así lo encontramos en el interrogatorio de Cristóbal de la Cruz, hortelano, quien declara que el año passado que no se acuerda en que mes estando la de Cruz, muger deste que declara, vn día de fiesta según quieren decir bendiendo passó por la dicha puerta fulano Serrano $^{37}$. Descripción que apenas nos arroja datos para identificar el delito. No nos indica el lugar en que se encuentra su mujer, el delito cometido, ni el nombre completo de los notarios que intervienen en la denuncia ni siquiera indica la fecha concreta en que se produjeron los acontecimientos. Generalidades que contrastan con la riqueza de datos que suministra este mismo testigo a la hora de narrar los acontecimientos que se desarrollaron a raíz de la detención de la mujer. Por él sabemos no solo los nombres de los notarios que están presentes en cada momento sino también la causa de la detención.

Los testigos deben ser lo más concretos posibles a la hora de realizar una acusación contra un notario. Deben identificar a las personas que intervienen en el proceso y el delito por el que son juzgados de forma clara y sin ambigüedades. Debiendo contestar en cada pregunta lo que saben indicando dónde estaba en ese momento, si lo oyó, a qué hora y quién estaba presente de manera que se pueda investigar y descartar si el testigo es sospechoso o de poco crédito ${ }^{38}$.

Dixo que lo que della sabe (primera pregunta del interrogatorio) es que munchas vezes allegan a llamar a los oficiales que están en los cajones de los dos oficios ques Pedro de Baldés y Christobal de Castilla para que vayan a desanimar testi-

\footnotetext{
AHDG. Leg. 230-F. Declaración de Antonio Gómez Barbero (2 de Enero de 1591).

AHDG. Leg. 230-F. Declaración de Antonio Gómez Barbero (2 de Enero de 1591).

AHDG. Leg. 230-F. Interrogatorio a Cristóbal de la Cruz (9 de Enero de 1591).

P. MELGAREJO, Compendio de contratos... p. 330.
} 
gos en casamientos fuera de la avdiencia y les dizen a las partes questán ocupados y no pueden yr y que no ay quien baya de cuya cavsa las partes les pagan más derechos de los que justamente les debe ${ }^{39}$.

De igual forma podemos encontrar varias comparecencias del mismo testigo, unas veces para completar o modificar sus declaraciones porque se les ha olvidado algún dato que considera importante para el proceso, o porque quiere incluir nuevas denuncias a la misma. Cuando un testigo formula una denuncia directa contra algún oficial de la Audiencia el juez cita de nuevo al denunciado para que justifique por qué actuó de esa manera; en caso de no llegar a un acuerdo se llama a nuevos testigos para que aleguen a favor o en contra de la denuncia estableciéndose un enfrentamiento dialéctico entre los testigos que acusan y los oficiales que o bien contraatacan o bien se defienden.

Puede ocurrir que algunos testigos en sus declaraciones citen a otras personas que conocen de primera mano los acontecimientos declarados y los identifican con la intención de que éstos sean citados para que le den veracidad a sus propias declaraciones. En este caso se sigue lo establecido en la práctica forense.

Assi mesmo el dicho juez ha de tener auiso al tiempo que haze la dicha información secreta de hazer aueriguación y verificación que quando el testigo de oydas que depone lo oyó a otra persona o personas si pudieren ser auidas las mande llamar y haga la dicha aueriguación con ellos ${ }^{40}$.

Por último, se observa una diferenciación entre las declaraciones de los testigos residentes en Granada capital y los residentes extrarradio de la zona de influencia, Alpujarra, Tahás y Vicarías. En el primer caso son los que presentan un mayor número de quejas con respecto a las actuaciones notariales. Por el contrario, en los situados en los lugares más alejados de la capital se observa una gran desidia en cuanto a la celebración de la residencia. En la mayoría de los casos no se pueden celebrar las probanzas por falta de testigos y en otras todos coinciden en que, salvo Magaña, los notarios han actuado correctamente cumpliendo con las obligaciones de sus cargos, que no hay quejas por parte de ningún vecino y que han cobrado los derechos de acuerdo al arancel del arzobispado ${ }^{41}$.

\section{Relación de cargos}

Es el momento en que se sacan a la luz las actuaciones contrarias al cumplimiento de las Constituciones Sinodales y a su aptitud como oficiales de la Audiencia. Surgen en dos momentos diferentes. El primero en la visita al oficio y la segunda tras la visita secreta. En la visita al oficio el juez hace relación de los cargos que se

\footnotetext{
AHDG. Leg. 230-F. Interrogatorio de Juan de Montiel (19 de Diciembre de 1590).

40 G. de MONTERROSO Y ALVARADO, Pratica ciuil y criminal..., fol. 246 r.

41 AHDG. Leg. 230-F.
} 
derivan de las desviaciones contra la praxis notarial sobre todo en lo relativo al inventario de escrituras y a la elaboración de los protocolos.

La segunda relación de cargos se produce, como ya hemos apuntado, una vez concluida la visita secreta y son los testigos los que ponen de manifiesto, a través de sus declaraciones, las faltas cometidas en el desempeño de su oficio o en su comportamiento como personal adscrito al arzobispado. Los cargos deben ser individuales para cada residenciado y no generales para todos. Normalmente, el juez toma en consideración las denuncias de cada uno de los testigos pero en los casos de delitos más graves como el cohecho éstos deben ser denunciados por tres testigos diferentes una vez comprobado que no existe animadversión hacia el residenciado.

El 17 de febrero de 1591 ya se había realizado la visita secreta a los notarios propietarios y al resto del personal del Tribunal ${ }^{42}$ y se procedió a dar traslado de los cargos que habían resultado contra ellos concediéndoles un plazo de seis días para que hicieran sus descargos. Plazo que debió ser prolongado pues todos alegan ser demasiado breve para poder defenderse de las acusaciones.

Entre los cargos más usuales destaca no hacer repartimiento de procesos; causas sin denuncia de fiscal o alguacil; no asentar los derechos en cada proceso; no haber firmado ni rubricado las notificaciones, ni los autos, ni las declaraciones de testigos; haber presentado autos de prórroga de término sin firma ni rubrica del juez ni de notario; tomar la declaración de testigos en minuta; haber cometido cohecho; haber hecho informaciones sin comisión ni mandato del juez y, sobretodo, no ser sufiçiente para el offiçio de notario ${ }^{43}$.

Asentar los derechos es una de las faltas más comunes que comenten los notarios. En las Constituciones Sinodales se manda asentar en cada proceso, en presencia de los imputados o de sus procuradores, los derechos que les corresponde, debiendo estar debidamente firmados y rubricados por las partes cosa que no acostumbran a realizar los notarios. Ellos se justifican diciendo que en las causas matrimoniales no tienen obligación de recogerlos sólo en los procesos y escrituras pues según declara Urbán Pérez, la dicha Costituçion sinodal diez y siete no se guarda ni está confirmada por el Consejo del Rey ${ }^{44}$.Los testigos, por su parte, declaran que es práctica común en la Audiencia no cobrar los derechos conforme al arancel establecido en la Diócesis que en ella no se gobierna por justiçia ni los derechos se lleban comforme a aranzel sino robando a los pleyteantes ${ }^{45}$.

Derivado del cobro de derechos está el cobro doble de derechos, cometer falsedad documental o coacción para cobrar más y la connivencia con otros notarios de la Audiencia para el reparto de derechos desmesurados.

42 AHDG. Leg. 230-F. También se les dio traslado a Luis de Prado, notario; Fabián de Baños, notario; Juan de Montiel, notario; Pedro de Sevilla, clérigo; Juan de Prado, alguacil; Jerónimo Serrano, notario y Francisco Guzmán, procurador.

43 AHDG. Leg. 230-F. Véase cuadro n 2 "delitos derivados de la mala praxis notarial".

44 CONSTITUCIONES sinodales del Arzobispado de Granada, 2a edición, Madrid, imprenta de Sancha, 1805, Título X. De officio notarii, et fide instrumentorum, Canon 17, p. 43. "No lleven más derechos de aquellos que nuestros jueces, o la persona que para ello estuviese diputada, les tasaren por las peticiones, autos, procesos, probanzas y escrituras que hicieren y ante ellos se presentaren y en cada proceso digan lo que llevaron. Y den fe de que los asentaron en presencia de quien se los pagó y este los firme si supiere o su procurador, so pena que lo vuelvan con el cuatro tanto de la primera vez, y la segunda doblado, la tercera parte para el denunciador".

45 AHDG. Leg. 230-F. Interrogatorio de Agustín de Ruelas (29 de Diciembre de 1590). 
...le dijo el fiscal: señor Ruelas déselos (se refiere al dinero que le pidió el notario por apartarlo del pleito) a Lorenço Adriano y conténtele que a mi no tiene que contentarme que después allá nos entenderemos nosotros... ${ }^{46}$.

También es frecuente que el pago de los derechos se hiciera de forma distinta a la establecida en el arancel del arzobispado y por tanto contraria a las Constituciones ${ }^{47}$. Así es normal encontrarlos en efectivo sin dar carta de pago a pesar de serle requeridos en numerosas ocasiones. De igual forma se acostumbra solicitar una parte en efectivo y la otra en especie fundamentalmente pellejos de vino, ropa como jubones de telilla de oro y plata, calzones o el alquiler o la compra de cabalgaduras para realizar los interrogatorios de testigos con residencia en los municipios limítrofes a Granada.

Junto al cobro de derechos se sitúa la toma de poderes y la declaración de los testigos en minuta. Hecho que contravenía el capítulo XXXIII del Titulo X de las Constituciones Sinodales bajo pena de privación del oficio por un año la primera vez y privación definitiva del oficio en caso de reincidencia ${ }^{48}$.

Hay cargos que van a tener una mayor gravedad en función de la persona a quien se les imputan. Así a Fernando Pérez Magaña, presbítero, se le va a acusar de vivir amancebado públicamente con una mujer, en las propias dependencias arzobispales, y de tener un hijo fruto de esta relación. Delito que va a tener una gran repercusión tanto por su calidad de sacerdote como por las causas que debe juzgar: las derivadas de la mala actuación de los clérigos, entre ellos el amancebamiento. ¿Cómo puede juzgar el amancebamiento de un eclesiástico alguien que lo está y que además es clérigo?

Fernando Pérez Magaña va a ser, sin duda, el notario que más escándalo provoque pues al amancebamiento se le va a unir pedir favores sexuales a las mujeres implicadas en los pleitos a cambio de favorecerlas en el juicio: dijo que lo que pasa es que el dicho Magaña entraua en casa desta testigo vna y muchas vezes y la requiria de amores promettiendola de faboreçerla ${ }^{49}$, dar cobijo en su casa a delincuentes buscados por el propio Tribunal y a mugeres de ruin bibir que han sido condenadas también por amancebamiento o llevar a su manceba al cimborrio o a la capilla mayor de la catedral ${ }^{50}$. En cuanto al desempeño de su oficio también es el que va a recibir más quejas por parte de sus compañeros de oficio y por el resto de los testigos. A las denuncias por realizar examen de testigos en presencia de otros testigos sin guardar el obligado secreto se unen las denuncias por ser inhábil en su oficio, pedir a otros notarios que despachen por él las causas con el provisor, o bien, pedirles que redacten los oficios que le pertenecen. Es el único de los que aparecen en la visita que fue recusado en varias causas.

\footnotetext{
46 AHDG. Leg. 230-F. Interrogatorio de Agustín de Ruelas (29 de Diciembre de 1590).

47 CONSTITUCIONES Sinodales, Título X. de officio Notarii, et FIDE instrumentorum, Canon 32, p. 48.

48 CONSTITUCIONES Sinodales..., p. 48.

49 AHDG. Leg. 230-F. Interrogatorio de Bernabela Ruiz de Montano (9 de Enero de 1591).

50 AHDG. Leg. 230-F. Interrogatorio de Juan de Prado (3 de Enero de 1591).
} 


\begin{tabular}{|c|c|c|c|c|c|c|c|c|c|c|c|c|c|c|c|c|c|c|}
\hline & $\stackrel{气}{E}$ & 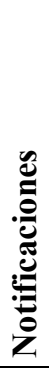 & 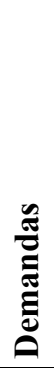 & & 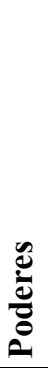 & 象 & 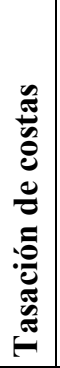 & 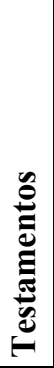 & : & 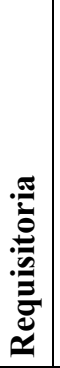 & 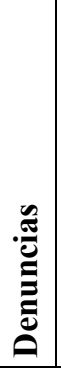 & 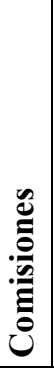 & 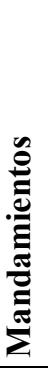 & 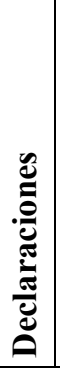 & 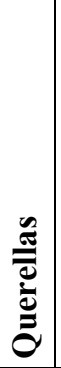 & 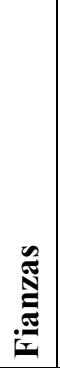 & 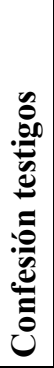 & 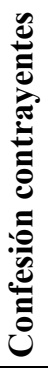 \\
\hline $\begin{array}{l}\text { Sin firma de } \\
\text { notario/juez }\end{array}$ & $\mathrm{X}$ & $\mathrm{X}$ & $\mathrm{X}$ & $\mathrm{X}$ & $\mathrm{X}$ & $\mathrm{X}$ & $\mathrm{X}$ & & & & & & $\mathrm{X}$ & $\mathrm{X}$ & $\mathrm{X}$ & $\mathrm{X}$ & & $\mathrm{X}$ \\
\hline Sin derechos & $X$ & $\mathrm{X}$ & $X$ & $\mathrm{X}$ & & & $X$ & & & & & & & & & & & \\
\hline Sin notificación & $\mathrm{X}$ & $\mathrm{X}$ & $\mathrm{X}$ & $\mathrm{X}$ & & & & & & & & & & & & & & \\
\hline Sueltos & $\mathrm{X}$ & & $\mathrm{X}$ & $\mathrm{X}$ & $\mathrm{X}$ & & & & & & & & $\mathrm{X}$ & & & & $X$ & \\
\hline $\begin{array}{l}\text { Sin rúbrica de } \\
\text { juez y/o notario }\end{array}$ & $\mathrm{X}$ & $\mathrm{X}$ & $\mathrm{X}$ & $\mathrm{X}$ & & $\mathrm{X}$ & $\mathrm{X}$ & & & & & & & & & & & \\
\hline Sin tasas & & $\mathrm{X}$ & & & & & $\mathrm{X}$ & & & & $\mathrm{X}$ & & & & & & & \\
\hline Sin repartir & & & $\mathrm{X}$ & $\mathrm{X}$ & & & & & & & $\mathrm{X}$ & & & & & & & \\
\hline $\begin{array}{l}\text { Sin examen de } \\
\text { testigos }\end{array}$ & & & & & & & & & & & & & & & & & & \\
\hline $\begin{array}{l}\text { Sin firma de } \\
\text { alguacil }\end{array}$ & & & & $\mathrm{X}$ & & & & & & & & & & & & & & \\
\hline $\begin{array}{l}\text { Sin mandar } \\
\text { cumplir }\end{array}$ & & & & & & & & & & $\mathrm{X}$ & & & & & & & & \\
\hline $\begin{array}{l}\text { Sin firma de } \\
\text { testigos }\end{array}$ & & & & & & & & & & & & & & & & & $\mathrm{X}$ & \\
\hline Sin comisión & $\mathrm{X}$ & & & & & & & & & & & $\mathrm{X}$ & & & & & $\mathrm{X}$ & \\
\hline $\begin{array}{l}\text { Tomadas ante } \\
\text { notario y no ante } \\
\text { juez }\end{array}$ & & & & & & & & & & & & $\mathrm{X}$ & & & & & & $\mathrm{X}$ \\
\hline Sin firma & & & & & & & & & $\mathrm{X}$ & & & & & & & & & \\
\hline Sin cabeza ni pie & & & & & & & & $X$ & & & & & & & & & & \\
\hline
\end{tabular}

Cuadro $\mathrm{n}^{\mathrm{o}}$ 2. Delitos derivados de la mala praxis notarial.

\section{El período de prueba}

Se inicia con el pliego de descargos presentados por el residenciado consiste en la justificación de su modo de actuar y en él se van contestando cada una de las acusaciones. En esta etapa el notario insiste en que no ha habido malicia para actuar así y que, por tanto, no hay ni culpa ni delito y en caso de duda debe tenerse en cuenta la calidad de su persona. Uno de los argumentos más utilizados en su defensa es el que se refiere a no haber actuado contra lo establecido en las Constituciones Sinodales que rigen a la diócesis, sino que su modo de proceder responde a la costumbre y al estilo aprobado por los jueces y que, por tanto, es conforme a estas disposiciones. 
Otro de los subterfugios utilizados por los notarios para su defensa es minimizar la gravedad de los delitos cometidos por su mala praxis o derivados de su comportamiento personal. En este caso piden no ser recriminados y ser exonerados de cualquier pena.

Lo normal en el descargo es culpar a otros notarios de su mala actuación o bien aducir que han actuado por delegación del notario encargado de resolver el pleito y que, por tanto, no son responsables de la mala gestión. Acusación que da lugar a la apertura de una nueva etapa de alegaciones por parte de los notarios implicados. Este es el caso de Fernando Pérez Magaña que en su descargo acusa a Pedro Herriega Valdés y a Juan de Montiel de haber actuado mal en las actuaciones tramitadas en su nombre ${ }^{51}$.

Al igual que había ocurrido durante la visita al oficio el notario, tras el pliego de descargos, dispone de un breve plazo de tiempo para presentar testigos que hablen bien de él justificando sus acusaciones o su forma de actuar o bien culpando a otro notario de su mala gestión.

\section{Sentencia}

Una vez concluido el periodo de prueba el juez de la visita Justino Antolínez procede a dictar sentencia definitiva contra los notarios propietarios del Tribunal Eclesiástico sobre los cargos observados y denunciados tanto durante la visita al oficio como en la secreta. Fueron pronunciadas a finales del mes de septiembre de 1591 continuando hasta marzo del siguiente año por problemas con uno de los notarios propietarios, Lorenzo Adriano.

La sentencia tiene como finalidad hacer responsable al notario de las faltas cometidas en el desempeño de su oficio indicando si obró bien o mal y debe ser ejecutada aunque sea suspensión o privación de oficio a tenor de lo dispuesto en la Sesión I, Capítulo X del Concilio de Trento ${ }^{52}$. Las penas se imponen en función de los cargos en los que han sido hallados culpables. Por tanto hay unas, que afectan al desempeño del oficio, sobre todo, de privación por un periodo, normalmente, de un año y para los casos más graves de excomunión a los que, públicamente, se negaran a cumplir con la pena impuesta. Y otras de carácter económico para los errores cometidos durante la tramitación de los expedientes y causas. Éstas deben ser abonadas en el plazo improrrogable de tres días tras la notificación de la sentencia y se aplican, generalmente, al pago de la visita.

Una vez pronunciada la sentencia definitiva, y depositado el dinero de las multas ante persona abonada señalada por el juez ${ }^{53}$, el notario dispone de diez días para aceptarla o apelar ante el Papa, el nuncio o su delegado. La apelación sólo se puede realizar contra la sentencia dictada por delitos probados en la visita secreta y no en la del oficio aunque el notario esté condenado a privación o suspensión de oficio según establece el Concilio de Trento ${ }^{54}$. Las apelaciones se pueden hacer hasta en

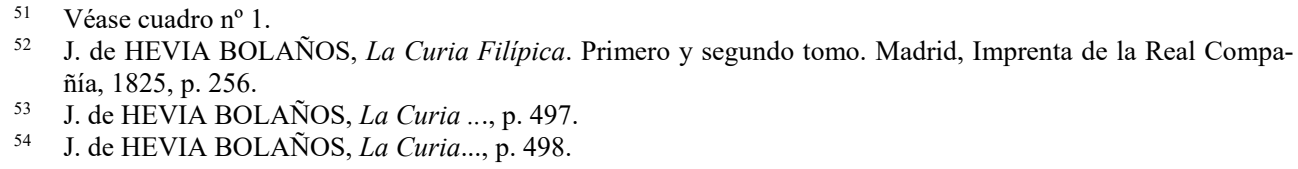


tres instancias consecutivas subiendo de grado en grado hasta acabar la vía y el notario que quiere apelar tiene, obligatoriamente, que solicitar, en el plazo de treinta días, testimonio de los autos en un término establecido por el juez. En caso contrario la apelación queda desierta y la sentencia será firme.

Las sentencias de los tres notarios propietarios del Tribunal Eclesiástico van a ser diferentes en función de la gravedad de las faltas cometidas. Así, en lo que respecta a Fernando Pérez Magaña se le condena a que desde ese momento ejerza su oficio con más cuidado y diligencia. Que tase los autos y procesos que ante él pasen llevando los derechos según arancel y si no cumple con esto se le condena a un año de privación de oficio. Sin embargo, y a pesar de los testimonios presentados contra él que prueban su falta de moralidad y que habían quedado suficientemente probados, no fue condenado por ninguno de ellos.

Un caso particular es el de Lorenzo Adriano solo se le condenó a una pena económica por infracciones cometidas en la tramitación de las causas. Condena que considera desproporcionada en función de los delitos cometidos. Él se justifica diciendo que solo ha sido acusado de tener oficios sin firmar y los procesos sin repartir y, por tanto, son delitos menores y no merecen el castigo impuesto, también aprecia irregularidades en la conclusión de su proceso al no haberle sido entregadas las actuaciones para poder realizar la apelación. En consecuencia, decide apelar sin hacer efectivo el pago de la multa de doscientos treinta reales hecho que contraviene las disposiciones legales para poder realizar cualquier tipo de apelación $^{55}$.

La situación se seguirá enrareciendo pasando de la jurisdicción eclesiástica a la civil e iniciando en la Chancillería un pleito por vía de fuerza contra el juez. El proceso concluyó en febrero del año siguiente 1592 condenando a Justino Antolínez a hacer entrega de las apelaciones a la vez que se le obliga a declarar nulas todas las actuaciones, sentencias y censuras que se hubieran producido contra Lorenzo Adriano y en el caso de no cumplir lo ordenado se le condena a la perdida de naturaleza y temporalidades y al pago de cincuenta mil maravedíes para la Cáma$\mathrm{ra}^{56}$. El proceso continuó hasta la conclusión de la residencia momento en el que Antolínez deja de tener jurisdicción y tanto el pleito como el cumplimiento de la sentencia contra Adriano quedan en suspenso ${ }^{57}$.

Es posible, aunque no frecuente, que la sentencia sea absolutoria para el notario visitado en cuyo caso es declarado fiel y legal y de confiança en el oficio ${ }^{58}$. Este es el caso de Urbán Pérez al que solo se le aprecian dos faltas consideradas de menor entidad, no haber sentado derechos en las causas matrimoniales y presentar algunos testimonios de testigos sin firmar. Por todo ello sólo se le condenó a una pena simbólica de trescientos maravedíes declarándolo absuelto de toda culpa.

55 Entre las cosas contra las que reclama está el no haberle sido entregado los procesos para hacer los descargos, no haberle sido notificado el auto de conclusión del proceso por lo que la sentencia era nula y el impedirle la apelación.

56 AHDG. Leg. 230-F. Sentencia de Lorenzo Adriano (30 de Septiembre de 1591).

57 D. CAVALARIO, Instituciones de Derecho Canónico. $2^{\mathrm{a}}$ ed. Tomo III. Valencia, Librería de Mallen y sobrinos, 1837, p. 129.

58 AHDG. Leg. 230-F. Sentencia de Urbán Pérez (30 de Septiembre de 1591). 


\section{Visita al resto de notarios}

De forma coetánea a la visita a los notarios propietarios se procedió a realizar la del resto del personal del Tribunal, notarios del cajón, notarios, nuncios y receptores. Los delitos son semejantes a los formulados a los notarios propietarios en cuanto a la queja generalizada de cobrar derechos en demasía, empezar uno las diligencias y terminarlas otro notario o presentar declaraciones de testigos sin firmar pero cambian en el momento en que se les inspecciona sobre la espinosa cuestión de tener comisión particular por escrito de los jueces o de los notarios propietarios para hacer las denuncias, informaciones sumarias y examen de testigos de los procesos que se realizan dentro de la capital o, por el contrario, solo tener una comisión general realizada verbalmente para los sustanciados fuera del Tribunal.

La costumbre de tener solo una comisión general verbal se remonta al pontificado de Pedro Guerrero (1546-1576) cuando se autoriza a todos los notarios, y no sólo a los propietarios, a hacer informaciones sumarias contando solamente con una comisión general de carácter verbal del provisor o notario propietario y no una específica y por escrito para cada una de las actuaciones ${ }^{59}$. Al ser un procedimiento más abreviado y rápido se acabó imponiendo en las actuaciones del Tribunal. La llegada del nuevo arzobispo Pedro de Castro y la necesidad de establecer unas normas para todos semejantes a las costumbres que rigen los tribunales reales supone un nuevo cambio en el procedimiento para realizar las actuaciones que no iban a ser ni aceptadas ni entendidas por los notarios.

Los notarios se niegan a introducir este nuevo procedimiento pues alegan que siempre se ha hecho así, que solo basta ser notario aprobado para poder realizar las actuaciones y que esto no contraviene ningún capítulo de las Constituciones. Frente a esta postura se posiciona el juez de la visita como representante del ordinario quien insiste en la obligación de presentar para cada actuación una comisión firmada y rubricada por el provisor, juez o por el notario propietario; de lo contrario cualquier actuación sería nula de pleno derecho. Postura que va a quedar reflejada en las sentencias publicadas durante la visita pues en ellas se va a condenar a los notarios a que no realicen ninguna información sin contar con las comisiones por escrito del provisor o juez correspondiente bajo pena de suspensión de oficio que oscila entre seis meses y un año ${ }^{60}$.

En cuanto a la sentencia, el modo de proceder es semejante al de los notarios propietarios. La mayoría son declarados por fiel y diligente notario y condenados a pagar una multa más o menos cuantiosa así como las costas que se aplican a los gastos de las visitas.

Al igual que ocurre con la visita de los notarios propietarios y tras hacer el depósito de la multa alegan contra la pena impuesta al considerarse agraviados por la misma anunciando que recurrirán ante la sede apostólica en defensa de sus derechos.

\footnotetext{
59 Los provisores durante estos pontificados fueron: Miguel González de Prida en tiempos del arzobispo Pedro Guerrero; Antonio Barba, Antonio de Tolosa durante la sede de Juan Méndez Salvatierra y Pedro Guerrero en la sede vacante de este último.

60 AHDG. Leg. 230-F. Sentencia contra Jerónimo Serrano de Vargas (30 de Septiembre de 1591).
} 


\section{Consecuencias de la visita}

Como en tantas otras ocasiones los resultados de la visita y las medidas adoptadas en ella fueron causa de nuevas oposiciones y críticas hacia el arzobispo Pedro de Castro esta vez por parte de los notarios eclesiásticos que prestan sus servicios en el Tribunal Eclesiástico. Oposición que se aprecia cuando sus biógrafos hacen relación de la visita. Tenemos que ponerlos en situación y tener presente las personalidades que intervienen en el conflicto, don Pedro hombre enérgico y de fuerte carácter que no acepta las críticas ni las correcciones y los notarios acostumbrados a trabajar sin ningún control ni directriz por parte de los arzobispos anteriores. Teniendo en cuenta estas dos premisas podemos entender las palabras de Justino Antolínez cuando dice: visitó los prouisores, visitadores y ministros de la sede vacante y su Audiencia, hiçose sauer a los notarios y ofiçiales i conocieron quan diferente estilo deuian guardar ${ }^{61}$.

En esta misma línea se sitúa el informe que realiza Pedro de Castro para la visita ad limina de 1594 en la que hay una clara alusión al estado de dejación que existe en el Tribunal Eclesiástico a la hora de la tramitación de los expedientes y causas. La referencia se produce cuando narra la situación en la que se encuentra la moralidad de la ciudad. Dice:

Lo moral está muy trauajado yerbe todo de pecados reduzido a recreación y deleite el peccar y dificultoso de gouernarse ni podemos remediar nada, los prelados los que auían de auidarnos, qualquier suerte que sea de gente, nos ponen impedimentos, todo está oppuesto y en contradición y imbaraços. En llegando a papel y tinta no se haze nada. Luego entra la apellación y la fuerça y está en tal estado que quizá sería peor que hablásemos. Emos de procurar el remedio con artificio. Están las cossas para nos yr a los yermos y andar siempre llorando, como Hieremias. Es materia muy larga ${ }^{62}$.

En términos parecidos se expresa el propio don Pedro en otro informe remitido, esta vez, al Consejo Real en diciembre de 1601 en el que aprovechando la defensa en la utilidad de la fundación del Colegio de las Recogidas hace una dura crítica a la actitud de los notarios del Tribunal. En él se dice:

Los notarios seglares y eclesiásticos y procuradores y otros officiales no lleuan bien que aya esta casa porque les falta la ganancia y prouecho que solían tener quando estos negocios lleuaban el corriente ordinario. Ase remediado también y atajado y continua diciendo..... y no de poco momento que se consigue con la casa de las Recogidas es euitar vna gran multitud de causas y pleytos injustos que cada día auía en la Audiencia deste arçobispado a donde por causas leuíssimas y aún sin ellas muchas mugeres de la gente popular pedían diuorcio... ${ }^{63}$.

61 Archivo Abadía Sacro Monte (AASM). Fondo de Pedro de Castro Libro I, Parte III. fol 244 v.

62 AHDG. Leg. 89-R-4. Relaçión del estado y gouierno de la Yglesia Metropolitana del arçobispado de Granada. fol $24 \mathrm{r}$.

63 Archivo General de Simancas (AGS). Patronato Eclesiástico, 59. 
Es cierto que la finalidad de la visita es ver la actuación de los notarios en el desempeño de sus oficios e indicar si lo han desempeñado con corrección o no tras el pontificado del anterior arzobispo y de su sede vacante. Pero también es cierto que en una diócesis como Granada ésta era la forma más rápida de sacar a la luz las desviaciones cometidas en las formas de actuar del Tribunal y un medio para proyectar una reforma de las instituciones tan necesaria en una diócesis que había sido gobernada por una persona débil como había sido el pontificado de Juan Méndez Salvatierra.

Los informes nos dejan claro que la situación requería una rápida intervención por parte del arzobispo para corregir los defectos del Tribunal sin embargo, para lo único que sirvió la visita fue para sacar a la luz los problemas endémicos que acuciaban a la Audiencia y poner de manifiesto la necesidad de una reforma en profundidad. Sin embargo, don Pedro no pudo o no quiso poner en marcha esta reforma y los notarios siguieron actuando tal y como la costumbre había impuesto sin modificación alguna.

La situación se prolongó durante el siglo XVII y buena parte del XVIII y tendremos que esperar hasta 1762 para que otro arzobispo, esta vez Pedro Antonio Barroeta y Ángel, intente y consiga poner orden al Tribunal dividiendo los negocios por clases, reduciendo las notarías y poniendo e imponiendo una especialización a cada notario ${ }^{64}$.

\section{Bibliografía}

D. CAVALARIO, Instituciones de Derecho Canónico. $2^{\mathrm{a}}$ ed. Tomo III. Valencia, Librería de Mallen y sobrinos, 1837. p. 129.

M. J. COLLANTES DE TERÁN DE LA HERA, "El juicio de residencia en Castilla a través de la doctrina jurídica de la Edad Moderna", Historia, Instituciones, Documentos, N$^{\circ} 25$ (1998) pp. 151-184.

CONCILIO de Trento. Traducido por Ignacio López de Ayala. $3^{\circ}$ ed. Barcelona, imprenta de Sierra y Martí, 1828.

CONSTITUCIONES Sinodales del Arzobispado de Granada, Madrid, imprenta de Sancha, 1805.

F. L. FERRARIS, Bibliotheca canonica, juridica, moralis, theologica, necnon ascetica, polemica rubricistica, historica..., vol. V, Roma, 1760.

M. L. GARCÍA VALVERDE, "Los notarios apostólicos de Granada a través de las legislaciones civil y eclesiástica", Historia, Instituciones, Documentos, $\mathrm{n}^{\circ} 37$ (2010), pp. 87-108.

J. de HEVIA BOLAÑOS, La Curia Filípica. Primero y segundo tomo. Madrid, Imprenta de la Real Compañía, 1825.

M. A. LÓPEZ RODRÍGUEZ, Los arzobispos de Granada: Retratos y Semblanza, Granada, imprenta Santa Rita, 1993.

M. S. MARTÍNEZ, Librería de jueces utilísima y universal...Tomo I. Madrid: imprenta de Blas Román, 1774.

64 AAV, Sacra Congr. Concilii Relationes, Leg. 370 A. 
F. J. MARTÍNEZ MEDINA, "La Iglesia", en Historia del Reino de Granada. II. La época morisca y la repoblación (1502-1630). Granada, Universidad, El Legado Andalusí, 2000, pp. 251-308.

P. MELGAREJO, Compendio de contratos públicos, autos de partición, executivos $y$ de residencias. Madrid, imprenta y librería de Pedro José Alonso Padilla, 1748.

G. de MONTERROSO Y ALVARADO, Pratica ciuil y criminal e instrucción de escriuanos: diuidida en nueue tratados, Valladolid, por Francisco Fernández de Cordoba, 1563.

R. M. PÉREZ GARCÍA, "Visita pastoral y contrarreforma en la archidiócesis de Sevilla, 1600-1650", Historia, Instituciones, Documentos no 27(2000), pp. 205234. 